Article

\title{
Impact of a Cultivation System upon the Weed Seedbank Size and Composition in a Mediterranean Environment
}

\author{
Alessia Restuccia ${ }^{\circledR}$, Sara Lombardo * and Giovanni Mauromicale \\ Dipartimento di Agricoltura, Alimentazione e Ambiente (Di3A), University of Catania, via Valdisavoia 5, \\ 95123 Catania, Italy \\ * Correspondence: saralomb@unict.it; Tel.: +39-0954783421
}

Received: 16 July 2019; Accepted: 2 September 2019; Published: 5 September 2019

\begin{abstract}
The knowledge of the soil seedbank is crucial to predict the dynamics of weed communities and potential future problems in agroecosystem weed management. Therefore, the aim of this study was to evaluate the qualitative and quantitative variation of the potential and real weed flora as a function of different cultivation systems (namely organic, conventional and uncultivated) in a Mediterranean environment (Sicily, south Italy). The results proved that soil seedbank density was significantly different in superficial $(0-10 \mathrm{~cm})$ and deeper soil layers $(10-15 \mathrm{~cm})$ in both organic and conventional cultivation systems. Portulacaceae and Amaranthaceae were the dominant botanical families, although they achieved a higher total number of seeds $\mathrm{m}^{-2}$ under a conventional cultivation system than under organic and uncultivated ones. The whole weed flora was represented by 45 taxa, but the presence of the crop reduced the qualitative and quantitative composition of real weed flora. In conclusion, the knowledge of the seedbank size and composition, as well as the variation in time and space of real flora, may contribute to predict the dynamics of weed emergence and their possible interference with crops. In particular, information on the weed dynamics is essential to develop sustainable control protocols, especially under organic farming.
\end{abstract}

Keywords: seedbank; botanical family; cultivation system; soil layer depth; real weed flora

\section{Introduction}

Despite the significant advances in weed management technologies reached in the latest years, weed flora remains one of the most detrimental factors affecting crops' performance, as they are able to cause significant yield and quality losses [1]. While in developing countries, manual or mechanical weed management practices are prevalent, in developed ones the use of herbicides is dominant. Weed management outcomes strictly depend upon infestation size and composition [1], so that it is often necessary to adopt an integrated control approach (based on a combination of mechanical, cultural, biological and chemical management tools) to achieve an acceptable level of weed suppression [2]. As already reported in literature, cultivation systems may influence weed flora dynamics [3], and particularly, there is a growing interest by growers in the limitation of chemical weed control. Therefore, these eco-friendly cultivation systems rely more on cultural (crop rotation diversification and cover cropping) and mechanical weed control strategies [2]. In particular, the composition and abundance of weed flora in crop fields is mainly affected by crop rotation and soil tillage systems [4]. Crop rotation is an effective method of controlling weeds, since this modifies the weed seedbank and above-ground weed communities. However, the choice and sequence of crops may significantly affect weed community dynamics, because of their different biological cycle, end use, competition against weeds and crop management practices [1]. This should prevent the proliferation and dominance 
of certain weed species, by proving an unsuitable environment for them. Also tillage systems can influence the size and composition of a weed seedbank, since it may determine a vertical redistribution of seeds through the soil layers [5]. In addition, tillage modifies the soil environment, particularly its temperature, moisture, aeration and biological activity. For example, conservation tillage systems are frequently reported to increase weed infestations [5,6] and to rely upon higher herbicides use [7]. Therefore, there is a growing interest in the use of environmental sound strategies for weed suppression. In particular, the ecologically-based weed management practices (e.g., the use of cover crops, no-tillage or reduced tillage systems) are increasingly adopted in organic farming [2]. These nonchemical weed management tools may reduce the problems of herbicide resistance, environmental pollution, weed diversification and crop performance. However, the effectiveness of such strategies is more variable than the chemical weed management practices. In particular, the size of the weed seedbank is critical to the success of this ecologically-based weed control [8], since it can have long-lasting effects on crop yields; but it is not just the size of the seedbank, as seed germination may be impaired by allelopathic effects due to the phytotoxic activity of allelochemicals, introduced through crop rotations or by extracts applications [9]. Keeping in view all of the above-mentioned aspects, the knowledge of potential flora composition is essential to predict the weed cover of future infestations, and to develop integrated strategies for the management and control of weed flora [4,10-12], respecting environmental and economic constraints. The distribution of the seed stocks depends, indeed, upon the response of the spontaneous plant species (in terms of germination, seedlings survival, diffusion, etc.) to the different agricultural practices [13]. Although it is known that weeds' infestation strongly reduces crop yields $[13,14]$, no experimental data on the relationship between potential and real flora for organic agroecosystems, (in terms of weed seedbank and weed flora dynamics using a phytosociological approach), is reported. Therefore, the purpose of this study was to assess the qualitative and quantitative composition of the potential (seedbank) and real flora in a Mediterranean agroecosystem, as affected by the cultivation system (conventional, organic and uncultivated). A thorough knowledge of the impact of agricultural management practices on weed flora is fundamental to simultaneously developing control protocols capable of reducing the use of herbicides and to select a weed community with little impact on the agroecosystems.

\section{Materials and Methods}

\subsection{Experimental Site, Climate and Soil}

Field experiments were carried out in the coastal plain of Siracusa (Sicily-South Italy, $37^{\circ} 03^{\prime} \mathrm{N}$, $15^{\circ} 18^{\prime} \mathrm{E}, 10 \mathrm{~m}$ a.s.l.) in a moderately deep $(\sim 0.7 \mathrm{~m})$ calcixerollic xerochrepts soil [15] in the 2012 and 2013 seasons. The pre-experimental soil composition was: Clay $30 \%$, silt $25 \%$, sand $35 \%$, organic matter $2.0 \%$, pH 8.4 (slightly alkali), total nitrogen $0.18 \%$, available phosphorus 78 ppm, exchangeable potassium $337 \mathrm{ppm}$.

The local climate is semiarid-Mediterranean, with mild winters and hot, rainless summers. On average, the coolest month is January $\left(11.2{ }^{\circ} \mathrm{C}\right)$, while October $(111 \mathrm{~mm})$ and July $(2 \mathrm{~mm})$ are, respectively, the rainiest and the driest months. The mean temperature during the hottest month (August) is $25.1^{\circ} \mathrm{C}$; the local mean annual temperature is $18^{\circ} \mathrm{C}$ (Figure 1). On the basis of climatic data from 1965 to 1994 and the Rivas-Martinez bioclimatic indices, the whole sampling area may be classified within the thermo-Mediterranean inferior bioclimatic belt, with upper dry ombrotype [16]. 


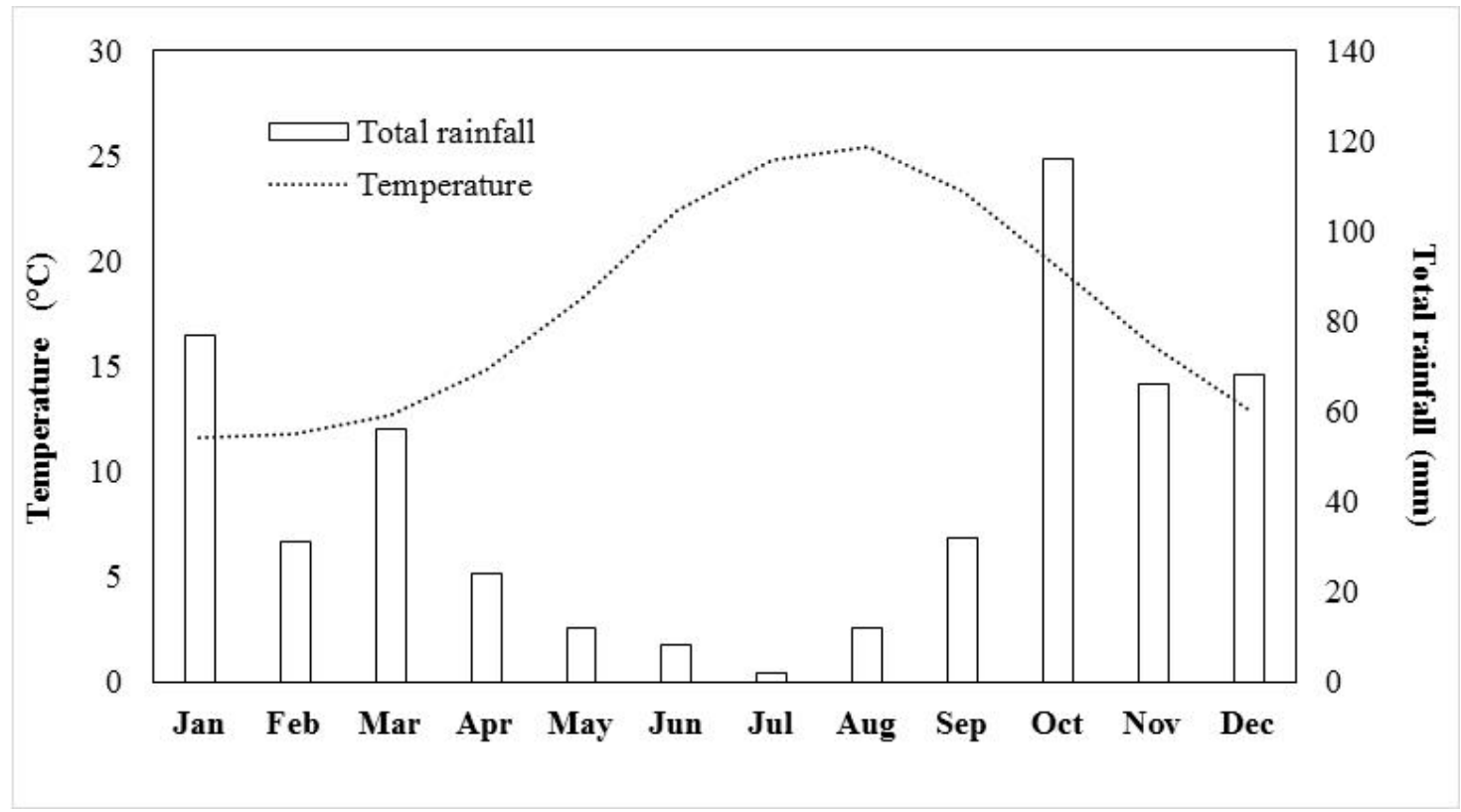

Figure 1. Climatic ombrothermic diagram at the experimental field site (average data from 1965 to 1994).

\subsection{Experimental Design and Management Practices}

The experiments included three treatments: Organic cultivation system (OCS), conventional cultivation system (CCS) and uncultivated plots (UCP), as a control. Each treatment, which included three replicate plots of $100 \mathrm{~m}^{2}(4 \times 25 \mathrm{~m})$, were separated by $25 \mathrm{~m}$-wide rows of Trifolium subterraneum L. cover cropping. The plots used for OCS and UCP were fully converted three years before our experimental trials by a period of crop rotation involving potato, globe artichoke and faba bean. The same crop rotation was adopted in the CCS.

For both OCS and CCS, in November 2012, seeds of Vicia faba L. subsp. major cv. Aguadulce, an early-maturing Spanish commercial genotype used for both fresh and dry seeds production, were hand sown at a depth of $4 \mathrm{~cm}$; inter-row spacing was $75 \mathrm{~cm}$, and the inter-plant spacing within the row was $33 \mathrm{~cm}$. Since faba bean had been previously grown in our experimental field, no supplemental inoculation of Rhizobium spp. was given in the soil. Prior to sowing, CCS was managed according to the local farming practices: tillage consisted of a $25 \mathrm{~cm}\left(10^{\prime \prime}\right)$ deep moldboard ploughing, followed by tine harrowing during the late summer; fertilization with $50 \mathrm{~kg} \mathrm{ha}^{-1}$ of $\mathrm{P}_{2} \mathrm{O}_{5}$ (as superphosphate) and $20 \mathrm{~kg} \mathrm{ha}^{-1}$ of $\mathrm{N}$ (as ammonium nitrate); weeds were controlled by hand when necessary. For OCS, in which synthetic herbicides are banned, soil was ploughed to a $10 \mathrm{~cm}\left(4^{\prime \prime}\right)$ depth during the late spring. The crop management (i.e., crop rotation, fertilization and protection of plants) in the OCS followed current European Union (EU) regulations (Regulation CE 834/2007, 889/2008, 967/2008, 1235/2008, $1254 / 2008$ and their modifications). UCP had no cultivation.

\subsection{Seedbank Sampling and Analysis}

In order to assess the spatial arrangement of weed seeds in the soil, in all three treatments, soil samples were collected every month (from November to September) at three different depths $(0-5 \mathrm{~cm}$, $5-10 \mathrm{~cm}$ and $10-15 \mathrm{~cm}$ ) using a $4 \mathrm{~cm}$ diameter steel probe. Along the diagonals of each $100 \mathrm{~m}^{2}$ sampling area ( $25 \mathrm{~m}$ length $\times 4 \mathrm{~m}$ width), a total of 990 soil cores $(10$ cores $\times 3$ soil depth layers $\times 11$ months $\times 3$ cultivation systems) were collected. The distance between sampling sites was $2.5 \mathrm{~m}$. Soil samples were stored for a few days at $4{ }^{\circ} \mathrm{C}$ in the dark, to prevent seed germination prior to identification.

Soil samples from each of the three soil layer depths were well-mixed and the inert fraction (stones, pebbles, etc.) was manually removed. For the direct seed extraction, seeds were separated from the soil by washing the sample with water. In order to have a better representation of the entire soil core, four 
(150 g) replicates for each soil layer were previously pre-treated with $5 \mathrm{~g}$ of sodium hexametaphosphate solution for $20 \mathrm{~min}$ to disperse the colloid matrix. To evaluate Orobanche seeds, because of their small size and specific weight, only the suspension was filtered through a series of different mesh sieves (from 5 to $300 \mu \mathrm{m}$ ) and then, after this sieving/floatation technique as described by Benvenuti and Macchia [11], they were observed by a MS5 stereo-microscope (Leica Microsystems, Wetzlar, Germany). The remaining solutions of each of the sub-samples were placed into a metal tube with a removable cap comprising a $250 \mu \mathrm{m}$ steel mesh and then were washed through an electric adjustable pressure (20-120 bar max) washer (Kärcher, K 3500 model, Winnenden, Germany). The extracted material was transferred to Petri dishes and then air-dried for the separation, identification and counting of the weed seeds with a stereo-microscope. The extracted seeds were submitted to the "seed crushing test" through slight finger pressuring for the assessment of viable seeds [17]. The values of viable seeds in each subsample were expressed as the number of seeds $\mathrm{m}^{-2}$ of surface area for each soil depth horizon [18].

The potential flora data were grouped as function of the botanical family, and each species was assigned to a life-form category considering the Raunkiaer system [19]. Then, with the aim of evaluating the effects of the cultivation system and soil layer on weed dynamics, we grouped these species into main botanical families (i.e., Portulacaceae, Amaranthaceae, Asteraceae, Primulaceae, Scrophulariaceae) and included the remaining ones into the 'others' group. The Orobanchaceae family was considered separately because of the heavy infestation of faba bean fields by Orobanche crenata Forsk [20].

\subsection{Weed Flora Analysis}

For the study of the real weed flora, in each plot (OCS, CCS and UCP) 16 permanent $0.5 \mathrm{~m}$ squares were randomly marked and monthly surveyed according to the scale proposed by Braun-Blanquet [21]. The reported technique has been widely applied in studies on agricultural systems and arable fields [22]. Such scale provides the following classes of cover: $5=75-100 \% ; 4=50-75 \% ; 3=25-50 \%$; $2=5-25 \%$; $1=$ numerous individuals, but less than $5 \%$, or scattered, with cover up to $5 \%$; $+=$ few individuals, with small cover; $r=$ rare, solitary, with small cover. The study allows the calculation of the number of plants rooted within each quadrat, as a measurement of the abundance or density of a single species. Each species was identified using different identification keys [23,24], and the nomenclature was given to each of them [25].

For all of the surveys, the normalized frequency of occurrence for each species was determined with the aim to assign each species to one of the five presence classes (I: 0-20\%; II: $20-40 \%$; III: $40-60 \%$; IV: $60-80 \%$; V: $80-100 \%$ ). Frequency, expressed as the proportion of total quadrats containing at least one rooted individual of a given species, was also used to determine the biological spectrum of the whole weed community analyzed.

\subsection{Statistical Analysis}

Levene's test was used to test homoscedasticity (or homogeneity of variance); data were then subjected to a three-way (cultivation system $\times$ soil layer $\times$ botanical family) analysis of variance (ANOVA). Means were separated by the least significance difference (LSD) test when the F-test was significant. Percent values were transformed to arcsin $\sqrt{ } \mathrm{x}$ (Bliss transformation) prior to being statistically analyzed; untransformed data were reported and discussed. All calculations and ANOVA were performed using CoStat ${ }^{\circledR}$ version 6.003 (CoHort Software, Monterey, CA, USA). 


\section{Results}

\subsection{Weed Species Richness}

The relative density (expressed as percentage of total seeds $\mathrm{m}^{-2}$ ) of each weed species in relation to the cultivation system and soil layer is reported in Table 1. In total, 32 taxa belonging to 18 botanical families were recorded in the three soil layer depths; $78 \%$ of which were therophytes, while the remainder were hemi-cryptophytes. No significant differences in terms of weed seedbank composition at different soil layer depths were found among the evaluated cultivation systems. Indeed, the data about weed seedbank showed that one species (Lolium multiflorum Lam.) was unique to the OCS, one (Veronica polita Fr.) was exclusively found in UCP and the others were present in all the cultivation systems (Table 1). In particular, Portulaca oleracea L. was the most dominant species in all the soil layer depths and cultivation systems with mean values ranging from 1883 to 4967 seeds $\mathrm{m}^{-2}$, followed by Amaranthus retroflexus L. with values ranging from 1583 to 2767 seed $\mathrm{m}^{-2}$. Both weed species mainly contributed to the total seed $\mathrm{m}^{-2}$ under CCS than under OCS and UCP (Table 1). For A. retroflexus, it is interesting to note that the number of seeds $\mathrm{m}^{-2}$ increased under both CCS and OCS, going from the superficial to the deeper soil layer, while the opposite trend was observed under UCP. Other weed species, i.e., Anagallis arvensis L., Fumaria officinalis L., Helminthotheca echioides (L.) Holub and Sonchus asper (L.) Hill were also widespread in all of the cultivation systems and soil layer depths, but showing mean values of density below 900 seeds $\mathrm{m}^{-2}$ (data not shown). Among the sporadic weeds, Fallopia convolvulus (L.) À. Love, Papaver rhoeas L. and Verbena officinalis L. were found in all the cultivation systems under study, despite the fact that they were absent in specific soil layer depths; while e.g., L. multiflorum and Sonchus oleraceus L. were recorded only in a few plots (Table 1).

\subsection{Weed Seedbank Density and Distribution for the Main Botanical Families}

ANOVA results indicated that, regardless of soil layer depth and botanical family, the total weed seedbank density was significantly higher in CCS $\left(31,650\right.$ seeds $\left.\mathrm{m}^{-2}\right)$ than in OCS and UCP $(26,200$ and 23,250 seeds $\mathrm{m}^{-2}$, respectively) (data not shown). However, both weed seedbank density and distribution were affected by the 'botanical family x cultivation system' (Figure 2) and 'botanical family x soil layer depth' (Figure 3) interactions. 
Table 1. Weed seedbank species composition and distribution (\% of total seeds) in relation to cultivation system and soil layer depth.

\begin{tabular}{|c|c|c|c|c|c|c|c|c|c|c|c|}
\hline \multirow{3}{*}{ Biological Group ${ }^{1}$} & \multirow{3}{*}{ Botanical Family } & \multirow[t]{2}{*}{ Cultivation System } & \multicolumn{3}{|c|}{$\mathrm{CCS}^{2}$} & \multicolumn{3}{|c|}{ OCS } & \multicolumn{3}{|c|}{ UCP } \\
\hline & & & \multicolumn{3}{|c|}{ Soil Layer Depth $(\mathrm{cm})$} & \multicolumn{3}{|c|}{ Soil Layer Depth (cm) } & \multicolumn{3}{|c|}{ Soil Layer Depth $(\mathrm{cm})$} \\
\hline & & Species & $0-5$ & 5-10 & $10-15$ & $0-5$ & 5-10 & 10-15 & $0-5$ & 5-10 & 10-15 \\
\hline $\mathrm{T}$ & Amaranthaceae & Amaranthus retroflexus $\mathrm{L}$. & $32.3 \pm 2.9$ & $27.4 \pm 1.3$ & $17.1 \pm 1.2$ & $27.8 \pm 2.5$ & $18.2 \pm 1.4$ & $15.7 \pm 2.4$ & $16.8 \pm 1.3$ & $21.6 \pm 1.2$ & $23.5 \pm 1.1$ \\
\hline $\mathrm{T}$ & Primulaceae & Anagallis arvensis $\mathrm{L}$. & $5.2 \pm 0.7$ & $4.6 \pm 0.7$ & - & $6.8 \pm 1.0$ & $6.1 \pm 0.8$ & $4.1 \pm 0.5$ & $7.8 \pm 0.9$ & $9.9 \pm 0.9$ & $15.4 \pm 1.0$ \\
\hline $\mathrm{H}$ & Chenopodiaceae & Beta vulgaris $\mathrm{L}$. & - & $2.3 \pm 0.4$ & - & - & - & - & $1.2 \pm 0.2$ & $0.6 \pm 0.1$ & $0.7 \pm 0.1$ \\
\hline $\mathrm{T}$ & Chenopodiaceae & Chenopodium album $\mathrm{L}$. & $1.3 \pm 0.2$ & $0.9 \pm 0.1$ & - & $0.5 \pm 0.1$ & - & - & - & - & - \\
\hline $\mathrm{T}$ & Asteraceae & Conyza spp. & $0.9 \pm 0.1$ & $0.5 \pm 0.1$ & $0.5 \pm 0.1$ & $1.5 \pm 0.3$ & - & - & - & - & - \\
\hline $\mathrm{H}$ & Asteraceae & Crepis vescicaria $\mathrm{L}$. & $0.9 \pm 0.2$ & $0.5 \pm 0.1$ & - & $0.5 \pm 0.1$ & $1.7 \pm 0.3$ & $1.7 \pm 0.3$ & $1.2 \pm 0.2$ & - & - \\
\hline $\mathrm{T}$ & Euphorbiaceae & Euphorbia helioscopia L. & $0.9 \pm 0.1$ & - & $0.5 \pm 0.1$ & - & - & - & $1.8 \pm 0.4$ & $1.9 \pm 0.2$ & $2.9 \pm 0.5$ \\
\hline $\mathrm{T}$ & Polygonaceae & Fallopia convolvulus (L.) Á. Löve & $0.9 \pm 0.1$ & $0.9 \pm 0.1$ & - & - & $0.5 \pm 0.1$ & - & $2.4 \pm 0.3$ & $0.6 \pm 0.1$ & $1.5 \pm 0.4$ \\
\hline $\mathrm{T}$ & Papaveraceae & Fumaria officinalis L. & $0.9 \pm 0.1$ & $1.4 \pm 0.2$ & $1.1 \pm 0.3$ & $1.0 \pm 0.2$ & $3.5 \pm 0.6$ & $4.1 \pm 0.3$ & $4.8 \pm 0.3$ & $3.1 \pm 0.5$ & $2.9 \pm 0.2$ \\
\hline $\mathrm{T}$ & Papaveraceae & Fumaria parviflora Lam. & & $1.4 \pm 0.3$ & $1.1 \pm 0.4$ & - & - & - & $6.0 \pm 0.4$ & $2.5 \pm 0.4$ & $7.4 \pm 0.6$ \\
\hline $\mathrm{H}$ & Asteraceae & Galactites elegans (All.) Soldano & $1.3 \pm 0.2$ & - & $0.5 \pm 0.1$ & - & - & - & $1.2 \pm 0.2$ & $3.1 \pm 0.2$ & $0.7 \pm 0.1$ \\
\hline $\mathrm{T}$ & Boraginaceae & Heliotropum europeum L. & $0.4 \pm 0.1$ & - & $0.5 \pm 0.1$ & - & - & $0.8 \pm 0.1$ & - & - & - \\
\hline $\mathrm{T}$ & Asteraceae & Helminthotheca echioides (L.) Holub & $1.3 \pm 0.5$ & $1.4 \pm 0.2$ & $1.6 \pm 0.5$ & $1.5 \pm 0.3$ & $5.6 \pm 0.5$ & $3.3 \pm 0.4$ & $0.6 \pm 0.1$ & $4.3 \pm 0.3$ & $2.2 \pm 0.4$ \\
\hline $\mathrm{T}$ & Lamiaceae & Lamium amplexicaule $\mathrm{L}$. & - & - & - & - & $2.0 \pm 0.1$ & $0.8 \pm 0.1$ & $0.6 \pm 0.1$ & $3.1 \pm 0.4$ & $1.5 \pm 0.1$ \\
\hline $\mathrm{T}$ & Malvaceae & Lavatera trimestris $\mathrm{L}$. & $0.4 \pm 0.1$ & $0.9 \pm 0.2$ & - & - & $0.5 \pm 0.1$ & - & - & - & - \\
\hline $\mathrm{T}$ & Poaceae & Lolium multiflorum Lam. & 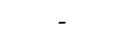 & - & - & - & $0.5 \pm 0.1$ & - & - & - & - \\
\hline $\mathrm{T}$ & Fabaceae & Lotus ornithopodioides L. & $0.4 \pm 0.1$ & - & - & - & - & - & - & $0.6 \pm 0.1$ & - \\
\hline $\mathrm{H}$ & Malvaceae & Malva rotundifolia $\mathrm{L}$. & 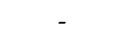 & - & $0.5 \pm 0.1$ & - & - & - & - & - & $0.7 \pm 0.1$ \\
\hline $\mathrm{H}$ & Orobanchaceae & Orobanche crenata Forsk. & $3.5 \pm 0.3$ & $4.1 \pm 0.6$ & $3.7 \pm 0.6$ & $4.9 \pm 0.8$ & $4.5 \pm 0.3$ & $4.1 \pm 0.4$ & - & - & - \\
\hline $\mathrm{T}$ & Papaveraceae & Papaver rhoeas L. & $0.9 \pm 0.2$ & - & $1.1 \pm 0.5$ & $1.0 \pm 0.2$ & - & - & $1.2 \pm 0.1$ & $4.9 \pm 0.4$ & - \\
\hline $\mathrm{T}$ & Poaceae & Polypogon monspeliensis (L.) Desf. & 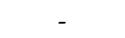 & - & $0.5 \pm 0.1$ & $0.5 \pm 0.1$ & - & - & - & - & - \\
\hline $\mathrm{T}$ & Portulacaceae & Portulaca oleracea L. & $43.7 \pm 1.5$ & $45.2 \pm 1.5$ & $52.9 \pm 2.8$ & $46.3 \pm 5.2$ & $43.9 \pm 1.7$ & $51.2 \pm 2.7$ & $28.7 \pm 2.8$ & $24.1 \pm 1.1$ & $19.1 \pm 1.6$ \\
\hline $\mathrm{H}$ & Asteraceae & Reichardia picroides (L.) Roth & - & $0.5 \pm 0.1$ & $0.5 \pm 0.1$ & - & $0.5 \pm 0.1$ & - & - & - & - \\
\hline $\mathrm{T}$ & Rubiaceae & Galium aparine L. & - & $0.5 \pm 0.1$ & - & - & $0.5 \pm 0.1$ & - & - & - & - \\
\hline $\mathrm{T}$ & Solanaceae & Solanum nigrum L. & - & - & $0.5 \pm 0.1$ & - & - & - & $3.0 \pm 0.5$ & $1.9 \pm 0.3$ & $2.2 \pm 0.3$ \\
\hline $\mathrm{T}$ & Asteraceae & Sonchus asper (L.) Hill & $3.5 \pm 0.9$ & $4.6 \pm 0.4$ & $6.4 \pm 0.8$ & $2.4 \pm 0.5$ & $8.1 \pm 0.8$ & $8.3 \pm 0.9$ & $13.8 \pm 1.0$ & $13.0 \pm 0.9$ & $18.4 \pm 1.1$ \\
\hline $\mathrm{T}$ & Asteraceae & Sonchus oleraceus L. & - & - & $3.2 \pm 0.7$ & - & - & - & - & $4.3 \pm 0.4$ & - \\
\hline $\mathrm{H}$ & Verbenaceae & Verbena officinalis $\mathrm{L}$. & - & - & $1.1 \pm 0.3$ & $0.5 \pm 0.1$ & $1.0 \pm 0.1$ & - & $0.6 \pm 0.1$ & - & - \\
\hline $\mathrm{T}$ & Scrophulariaceae & Veronica cymbalaria Bodard & - & - & $1.1 \pm 0.3$ & - & - & - & $5.4 \pm 1.0$ & - & $0.7 \pm 0.1$ \\
\hline $\mathrm{T}$ & Scrophulariaceae & Veronica hederifolia L. & $1.3 \pm 0.4$ & $3.2 \pm 0.5$ & $3.7 \pm 0.3$ & $3.9 \pm 0.3$ & $4.0 \pm 0.7$ & $4.1 \pm 0.4$ & - & - & - \\
\hline $\mathrm{T}$ & Scrophulariaceae & Veronica persica Poiret & - & & $1.6 \pm 0.3$ & $1.0 \pm 0.2$ & - & $1.7 \pm 0.2$ & - & - & - \\
\hline $\mathrm{T}$ & Scrophulariaceae & Veronica polita Fr. & - & - & - & - & - & - & $3.0 \pm 0.4$ & $0.6 \pm 0.1$ & - \\
\hline
\end{tabular}

${ }^{1} \mathrm{H}=$ hemicryptophytes; $\mathrm{T}=$ terophytes $;{ }^{2} \mathrm{CCS}=$ conventional cultivation system; $\mathrm{OCS}=$ organic cultivation system; $\mathrm{UCP}=$ uncultivated plots 


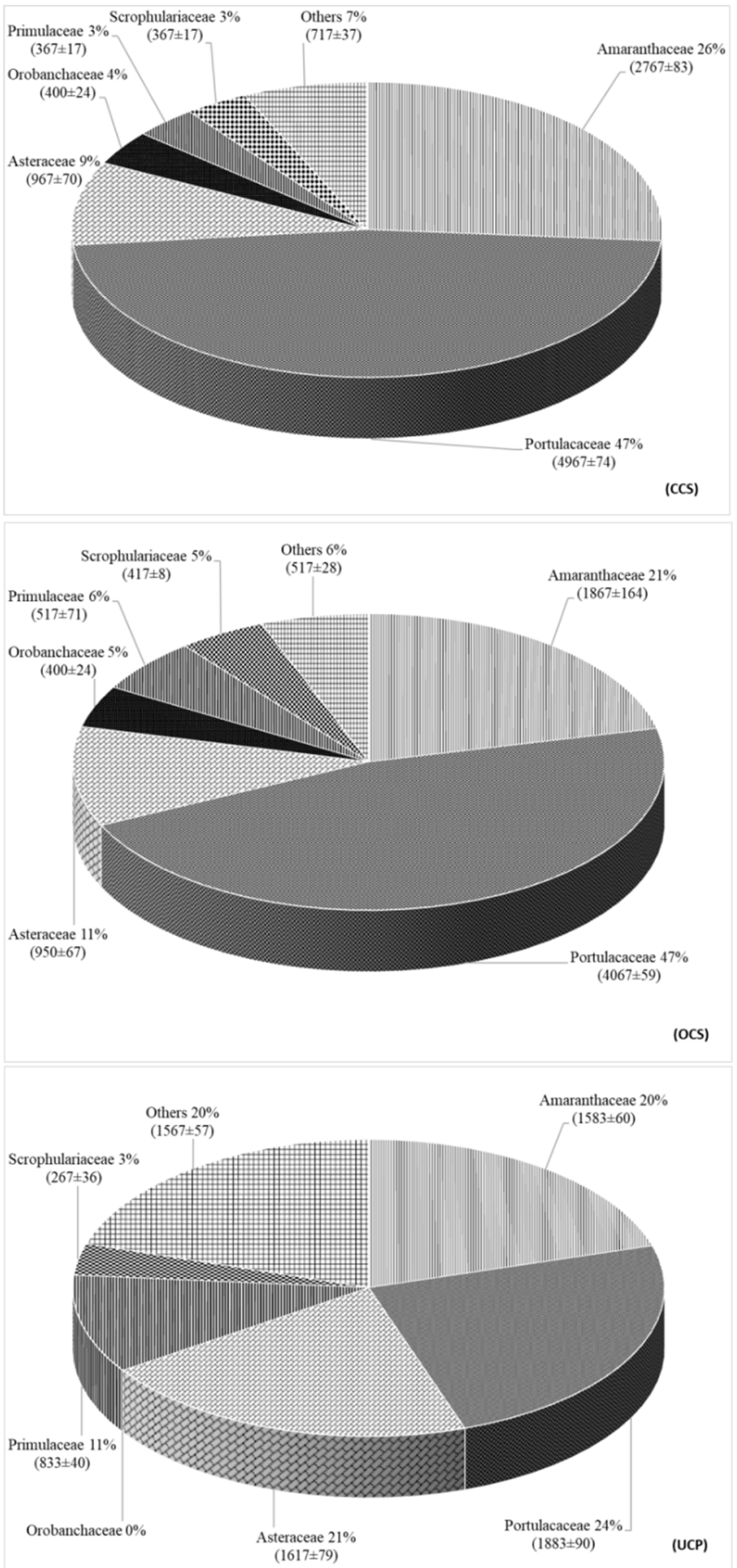

Figure 2. Total weed seedbank distribution (\%) and density (values in brackets and expressed as number of seeds $\mathrm{m}^{-2}$ ) as affected by the 'botanical family $\mathrm{x}$ cultivation system' interaction. CCS: Conventional Cultivation System; OCS: Organic Cultivation System; UCP: Uncultivated Plot. $\operatorname{LSD}_{\text {interaction }}(P \leq 0.05)=460$. 


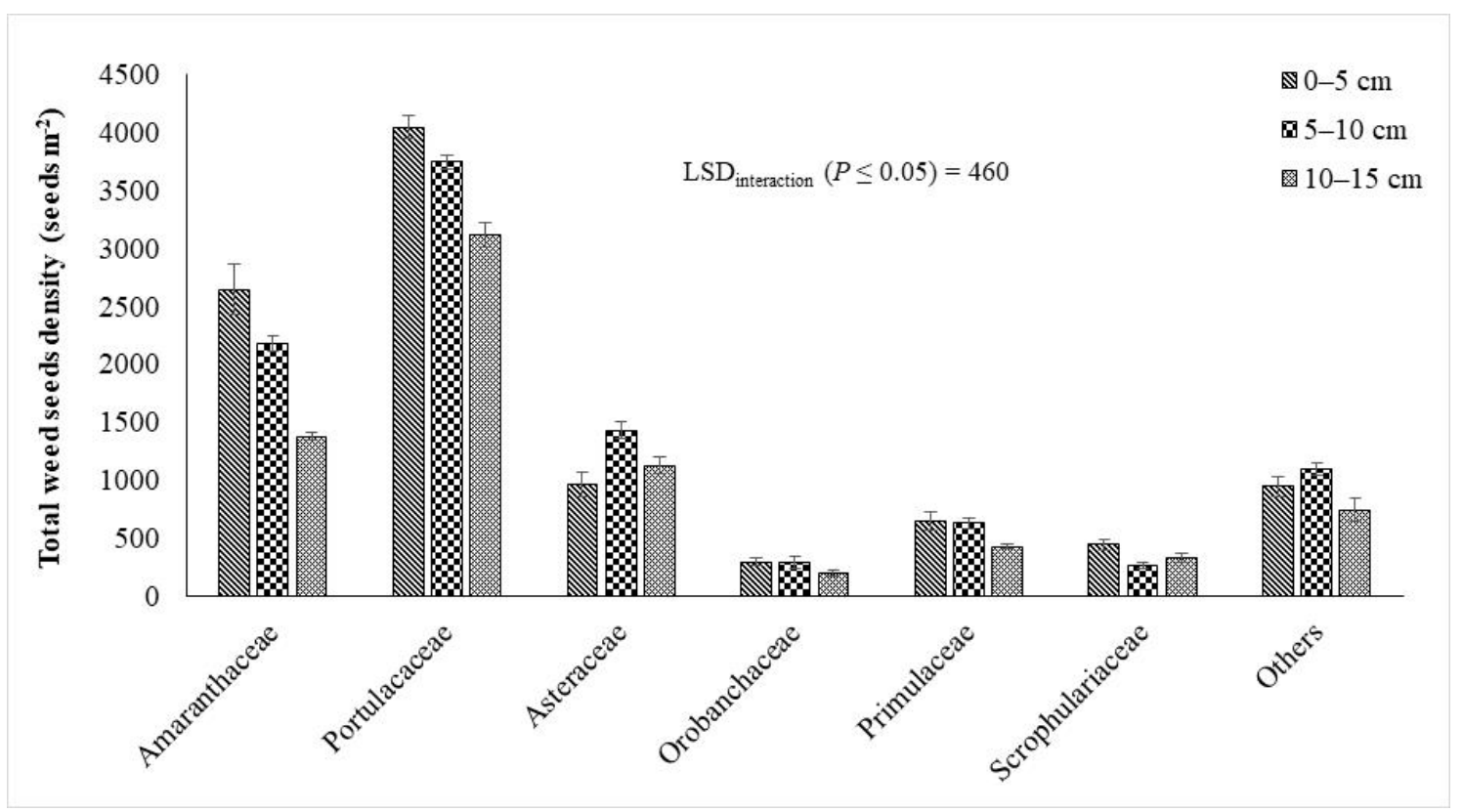

Figure 3. Total weed seedbank density $\left(\right.$ seed $\mathrm{m}^{-2}$ ) as affected by the 'botanical family $\times$ soil layer depth' interaction.

In both CCS and OCS Portulacaceae represented the main family accounting for, respectively, $47 \%$ and $26 \%$ of the total seeds $\mathrm{m}^{-2}$, followed by Amaranthaceae (respectively, $26 \%$ and $21 \%$ ) and Asteraceae (respectively, 9\% and 11\%) (Figure 2). Conversely, in UCP such botanical families were uniformly represented (24-20 and 21\%). In addition, both Portulacaceae ( 4967 vs. 4067 seeds m$^{-2}$ ) and Amaranthaceae ( 2767 vs. 1867 seeds $\mathrm{m}^{-2}$ ) achieved a higher total number of seed $\mathrm{m}^{-2}$ in CCS than in OCS. Primulaceae were more present in UCP than in the two cultivated plots (Figure 2). The same trend was observed for Papaveraceae, which contributed more to the 'others' group than the other botanical families (i.e., Chenopodiaceae, Euphorbiaceae, Fabaceae, Lamiaceae, Malvaceae, Polygonaceae, Solanaceae, Verbenaceae) (data not shown).

The weed seedbank density was significantly affected by the interaction between the botanical family and the soil layer depth (Figure 3). In each soil layer depth, Portulacaceae was the predominant botanical family followed by Amaranthaceae and Asteraceae. Going from the superficial $(0-5 \mathrm{~cm})$ to the deep $(10-15 \mathrm{~cm})$ soil layer, the amount of seeds per square meter was respectively reduced by $23.0 \%$ and $47.8 \%$ for Portulacaceae and Amaranthaceae, respectively. In contrast, the weed seed density of the other botanical families did not significantly differ among the three soil layers.

\subsection{Real Weed Flora}

The results demonstrated that the real flora, in terms of cover-abundance, is quite similar between the two cultivated plots, i.e., OCS and CCS (Figure 4).

In both CCS and OCS, Brassicaceae highlighted the highest values, followed by Papaveraceae, Euphorbiaceae, Asteraceae and Malvaceae. In UCP, together with Brassicaceae and Papaveraceae, the highest cover-abundance values were reported for Poaceae, Lamiaceae and Rubiaceae. Asteraceae and Euphorbiaceae showed significant differences among the two cultivated plots and UCP ( $23 \%$ vs. $4 \%)$, as also reported for Fabaceae (15\% vs. 4\%). UCP showed a significantly higher percentage of cover-abundance for Papaveraceae, Poaceae, Lamiaceae, Rubiaceae and Amaranthaceae than OCS and CCS.

Considering the normalized frequency of occurrence for each weed (Table 2), the component of species in class I was rather widespread, while only Galactites elegans (All.) Soldano, Malva rotundifolia L., Medicago polymorpha L. and P. rhoeas reached class V in all the evaluated cultivation systems. Other species such as F. convolvulus, H. echioides, S. asper and S. oleraceus were present at higher concentrations 
(classes IV and V) in all the three cultivation systems. By contrast, Avena sterilis L. and Lolium rigidum Gaud. exclusively appeared in the cultivated plots. Solanum nigrum L. and Veronica cymbalaria Bodard greatly reduced their presence in UCP, passing from class V (in the cultivated plots) to classes II and I, respectively. In UCP, on the contrary, Lamium amplexicaule $\mathrm{L}$. is widespread (class V), but almost absent in the two cultivated plots (for both class I).

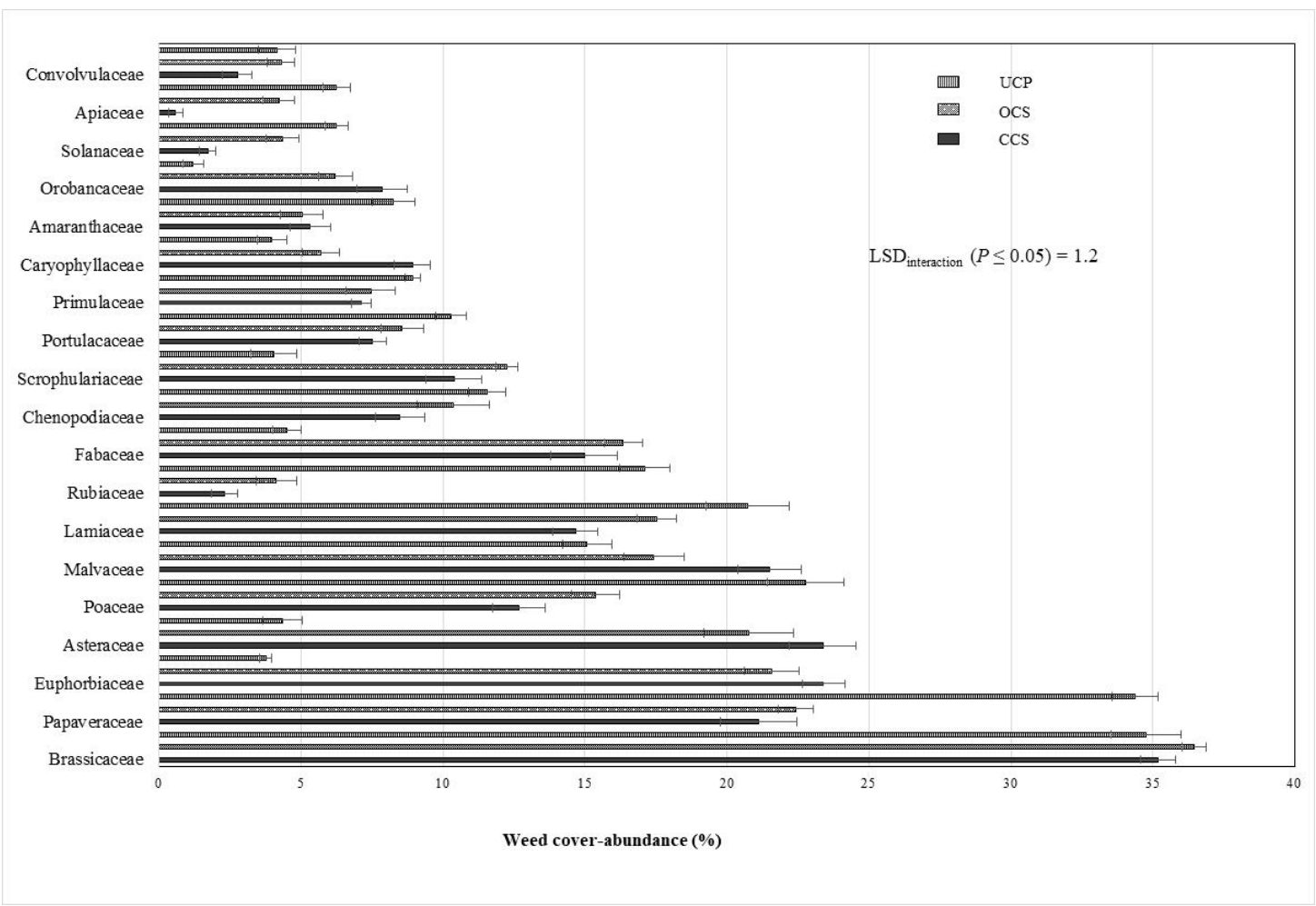

Figure 4. Percentage of weed cover-abundance as affected by the 'botanical family $\times$ cultivation system' interaction.

Table 2. Normalized frequency of occurrence [as expressed as presence classes (I: 0-20\%; II: 20-40\%; III: 40-60\%; IV: $60-80 \%$; V: 80-100\%)] for each investigated species in relation to the cultivation system (CCS: Conventional Cultivation System; OCS: Organic Cultivation System; UCP: Uncultivated Plot).

\begin{tabular}{cccc}
\hline & \multicolumn{3}{c}{ Cultivation System } \\
\cline { 2 - 4 } Species & CCS & OCS & UCP \\
\hline Amaranthus blitoides S. Watson & & & I \\
Amaranthus retroflexus L. & III & III & II \\
Anagallis arvensis L. & IV & IV & IV \\
Avena sterilis L. & V & IV & \\
Capsella bursa-pastoris (L.) Medik. & I & & I \\
Chenopodium album L. & I & & I \\
Chenopodium murale L. & & & II \\
Cynodon dactylon (L.) Pers. & & & III \\
Daucus carota L. & I & & II \\
Digitaria sanguinalis (L.) Scop. & & I & II \\
Diplotaxis erucoides (L.) DC. & & &
\end{tabular}


Table 2. Cont.

\begin{tabular}{|c|c|c|c|}
\hline \multirow[b]{2}{*}{ Species } & \multicolumn{3}{|c|}{ Cultivation System } \\
\hline & CCS & OCS & UCP \\
\hline Euphorbia chamaesyce L. & I & & \\
\hline Euphorbia helioscopia L. & I & I & II \\
\hline Euphorbia sp. & I & I & I \\
\hline Fallopia convolvulus (L.) Á. Löve & IV & $\mathrm{V}$ & $\mathrm{V}$ \\
\hline Fumaria officinalis L. & $\mathrm{I}$ & II & I \\
\hline Fumaria parviflora Lam. & I & I & $\mathrm{I}$ \\
\hline Galactites elegans (All.) Soldano & $\mathrm{V}$ & $\mathrm{V}$ & $\mathrm{V}$ \\
\hline Galium aparine L. & III & IV & II \\
\hline Glebionis coronaria (L.) Cass. ex Spach & $\mathrm{I}$ & II & $\mathrm{I}$ \\
\hline Helminthotheca echioides (L.) Holub & IV & $\mathrm{V}$ & $\mathrm{V}$ \\
\hline Lamium amplexicaule $\mathrm{L}$. & I & I & $\mathrm{V}$ \\
\hline Lavatera trimestris $\mathrm{L}$. & & I & I \\
\hline Lolium rigidum Gaud. & V & IV & \\
\hline Malva rotundifolia $\mathrm{L}$. & $\mathrm{V}$ & $\mathrm{V}$ & $\mathrm{V}$ \\
\hline Medicago arabica (L.) Huds. & I & I & \\
\hline Medicago polymorpha $\mathrm{L}$. & $\mathrm{V}$ & $\mathrm{V}$ & $\mathrm{V}$ \\
\hline Orobanche crenata Forsk. & IV & IV & . \\
\hline Papaver hybridum L. & III & II & I \\
\hline Papaver rhoeas L. & $\mathrm{V}$ & $\mathrm{V}$ & $\mathrm{V}$ \\
\hline Phalaris sp. & & I & \\
\hline Polycarpon tetraphyllum (L.) L. & & I & \\
\hline Portulaca oleracea L. & II & II & II \\
\hline Raphanus raphanistrum ssp. landra (Moretti) Bonnier & IV & IV & IV \\
\hline Reichardia picroides (L.) Roth & $\mathrm{I}$ & & \\
\hline Sinapis arvensis $\mathrm{L}$. & & I & II \\
\hline Sisymbrium officinale (L.) Scop. & & & II \\
\hline Solanum nigrum L. & IV & $\mathrm{V}$ & II \\
\hline Sonchus asper (L.) Hill & IV & $\mathrm{V}$ & $\mathrm{V}$ \\
\hline Sonchus oleraceus L. & $\mathrm{V}$ & IV & $\mathrm{V}$ \\
\hline Sonchus tenerrimus L. & III & II & I \\
\hline Torilis nodosa (L.) Gaertn. & & & I \\
\hline Trifolium subterraneum L. & & I & I \\
\hline Veronica cymbalaria Bodard & $\mathrm{V}$ & III & I \\
\hline Veronica polita Fr. & II & $\mathrm{I}$ & I \\
\hline
\end{tabular}

\section{Discussion}

A total of 32 species were detected with a prevalence of therophytes $(>78 \%)$ over hemy-cryptophytes, due to the short life cycle which enables therophytes to resist the high degree of anthropogenic disturbance caused by agricultural techniques [26]. Several studies [27-29] demonstrated that different cultivation systems can determine changes in the richness of weed species. In our study, significant differences in the total weed seedbank density were observed according to the following order: CCS $>$ OCS $>$ UCP. Indeed, the way in which each weed species may expand its habit range into agricultural environments, remaining as an invader, depends upon complex interactions [10]. Here, the high abundance of weed seeds $\mathrm{m}^{-2}$ in CCS was related to the high density of Portulacaceae and Amaranthaceae, with both botanical families represented by only a species (P. oleracea and A. retroflexus, respectively). In addition, a higher weed competition in UCP determined the decrease of the total weed seedbank density in the superficial soil layer depth for $P$. oleracea and through the first $10 \mathrm{~cm}$ of soil layer for $A$. retroflexus. With respect to these two species, our results are in good agreement with some previous studies which showed that they have long been problematic in the Mediterranean Basin.

Their presence under both organic and conventional cultivation systems $[5,13,17]$ may be explained by the high number of small seeds produced per plant, a good adaptation to the highly disturbed and moist conditions of irrigated field crops [30], as well as by their need for adequate moisture levels 
and good seed-soil contact to absorb moisture and germinate. Such biotic and abiotic factors may contribute to their higher seedbank density in all the cultivation systems under study. In particular, the high light intensity and high temperatures, typically experienced in the Mediterranean Basin [31] and usually found in tilled soils [32], can support the germination and establishment of P. oleracea in CCS, while A. retroflexus problems are common also in no-tillage systems with conventional herbicides, in which seeds are arranged on the soil surface and selected within herbicide-resistant populations [33]. However, high populations of such prolific species can be observed in both organic and conventional systems, in tilled and no-till systems. Both A. retroflexus and P. oleracea have specific characteristics that make them very invasive. As an instance, a single plant of $A$. retroflexus, which emerges, grows, flowers and forms mature seeds from late spring to autumn, can produce 100,000-600,000 seeds (1-1.2 $\mathrm{mm}$ in diameter), characterized by multiple dormancy mechanisms [34], depending on the environmental conditions experienced by the mother plant during seed maturation [35], allowing them to be persistent in the soil for long time periods. Because of their dimension, only seeds located within the first $10 \mathrm{~cm}$ of soil are able to germinate; while those buried in deeper soil layers become dormant and maintain their ability to geminate for several years when brought to the surface by minimum tillage or cultivation. P. oleracea, an r-strategist, can produce more than 10,000 seeds per plant [36], which are readily dispersed over short and long distances, and have a percentage of germination higher than $90 \%$ in $24 \mathrm{~h}$ under suitable conditions [36,37]. Their ability to produce a large number of small ( $0.5 \mathrm{~mm}$ in diameter) seeds in different environments and an excellent seed survival rate allow this weed species to enrich the soil seedbank in short time [38].

Based on our results, it is also worth mentioning that Amaranthaceae maintained a similar number of seeds $\mathrm{m}^{-2}$ in OCS and UCP. In contrast, CCS and OCS achieved a reduction of Primulaceae and Asteraceae seeds $\mathrm{m}^{-2}$; in addition both cultivated systems were characterized by a longer-term persistent seedbank [39] if compared to UCP. Probably the ecological conditions in undisturbed soils (absence of agronomic treatments), which may determine a limited soil aeration, inhibited seed germination, determining an accumulation of seeds in the soil [11].

The results on real weed flora composition and distribution showed that 45 species, belonging to 19 different botanical families, were present in the studied agroecosystem. In particular, both cultivated plots (OCS and CCS) showed a higher number of weed species belonging to class V than UCP. Indeed, the agricultural practices (sowing time, weed management control, fertilization, etc.) modify the physical, chemical and biological conditions of the soil, which may have influenced the emergence, growth and ability of some species to produce seeds, and thus their relative cover-abundance [1]. Moreover, as reported by many researchers $[40,41]$, several ecological factors (i.e., predation and decay) may determine a decrease of the number of weed seeds in the soil, as well as a high percentage of weed seeds that do not germinate probably because of their dormant state. Thus, a discrepancy between the soil seedbank and the standing vegetation is possible.

Some species, such as G. elegans, H. echioides, M. rotundifolia, M. polymorpha, P. rhoeas, S. asper and S. oleraceus, represent the most dangerous infesting weeds for cultivated crops. Our results showed that some dominant weed species identified through the floristic analysis, i.e., A. sterilis, L. rigidum and M. polymorpha, belonging to the class of presence $\mathrm{V}$, were underrepresented or even completely absent in the soil seedbank. Conversely, some plant species [i.e., Beta vulgaris L., Conyza spp., Crepis vescicaria L. Heliotropum europium L., Lotus ornithopodioides L. and Polypogon monspeliensis (L.) Desf.] present in the soil seedbank were poorly represented or even absent in the established weed flora. Also A. retroflexus and P. oleraceae, the dominant species in the soil seedbank, were poorly represented (presence class II) in the floristic cortege. Seed size significantly influences the survival of seedlings and can dramatically change the effect of the soil seedbank on the community composition. Moles and Westoby [42] reported that small-seeded plants were characterized by lower survival as seedlings, smaller canopies and shorter reproductive lifespans. 
In addition, some soil factors, such as moisture, organic content and seed density, may decrease seed survival due to a higher fungal activity [43] and thus would probably increase the mortality of small seeds over large seeds due to the difference in protection and nutrient reserves [42].

Amaranthus blitoides S. Watson, Chenopodium murale L., Daucus carota L., Sinapis arvensis L., Sisymbrium officinale (L.) Scop., Torilis nodosa (L.) Gaertn. and T. subterraneum are more sensitive to the presence of crops and, for this reason, they were present only in the uncultivated plots. Conversely, A. sterilis, Capsella bursa-pastoris (L.) Medik., Digitaria sanguinalis (L.) Scop., Euphorbia chamaesyce L., Galium aparine L., Glebionis coronaria (L.) Cass., L. rigidum, Medicago arabica (L.) Huds., M. polymorpha, Papaver hybridum L., Polycarpon tetraphyllum L., Raphanus raphanistrum ssp. landra (Moretti) Bonnier and Sonchus tenerrimus L. were the only species observed in the cultivated plots. Some of them were typical ruderal helio-subnitrophilous therophytic weeds.

\section{Conclusions}

Overall, our study provided useful information about the effects of cultivation systems on the weed population dynamics in a Mediterranean environment. Results indicated that cultivated (organic and conventional) systems determine the abundance of weed species in the soil seedbank, although the differences in composition are rather small. From a practical point of view, the qualitative and quantitative knowledge of the soil weed flora, as well as the spatial arrangement of weed seeds through the soil layer depths, can help in predicting the dynamics of weed emergence and interference with the cultivated crop. In particular, bio-ecological information on the behavior of weed dynamics are fundamental to develop sustainable weed control protocols, especially under organic farming. Thus, further research should be carried out to evaluate the effects of eco-friendly weed management tools (such as soil solarization, false sowings and direct seeding) on seeds' viability and germination.

Author Contributions: All the authors equally contributed to the conceptualization, methodology and investigation, as well as to the data curation and writing-original draft preparation.

Funding: This research received no external funding.

Conflicts of Interest: The authors declare no conflict of interest.

\section{References}

1. Ruisi, P.; Frangipane, B.; Amato, G.; Badagliacca, G.; Di Miceli, G.; Plaia, A.; Giambalvo, D. Weed seedbank size and composition in a long-term tillage and crop sequence experiment. Weed Res. 2015, 55, 320-328. [CrossRef]

2. Mirsky, S.B.; Gallandt, E.R.; Mortensen, D.A.; Curran, W.S.; Shumway, D. Reducing the germinable weed seedbank with soil disturbance and cover crops. Weed Res. 2010, 50, 341-352. [CrossRef]

3. Froud-Williams, R.J. Changes in weed flora with different tillage and agronomic management systems. In Weed Management in Agroecosystems: Ecological Approaches; Altieri, M.A., Liebman, M., Eds.; CRC Press: Boca Raton, FL, USA, 1988; pp. 213-236.

4. Ball, D. Weed seedbank response to tillage, herbicides, and crop rotation sequence. Weed Sci. 1992, 40, 654-659. [CrossRef]

5. Dorado, J.; Del Monte, J.P.; Lopez-Fando, C. Weed seed bank response to crop rotation and tillage in semiarid agro-ecosystems. Weed Sci. 1999, 47, 67-73. [CrossRef]

6. Cardina, J.; Herm, C.P.; Doohan, D.J. Crop rotation and tillage system effects on weed seedbanks. Weed Sci. 2002, 50, 448-460. [CrossRef]

7. Worsham, A.D. Role of cover crops in weed management and water quality. In Proceedings of the International Conference of Soil and Water Conservation Society, Ankeny, IA, USA, 9-11 April 1991; pp. 141-145.

8. Forcella, F.; Eradatoskoui, K.; Wagner, S.W. Application of weed seedbank ecology to low-input crop management. Ecol. Appl. 1993, 3, 74-83. [CrossRef]

9. Schreiber, M.M. Influence of tillage crop rotation, and weed management on giant foxtail (Setaria faberii) population dynamics and corn yield. Weed Sci. 1992, 40, 645-653. [CrossRef] 
10. Ghersa, C.M.; Martìnez-Ghersa, M.A. Ecological correlates of weed seed size and persistence in the soil under different tilling systems: Implications for weed management. Field Crop Res. 2000, 67, 141-148. [CrossRef]

11. Benvenuti, S.; Macchia, M. Seedbank reduction after different stale seedbed techniques in organic agricultural systems. Ital. J. Agron. 2006, 1, 11-21. [CrossRef]

12. Cristaudo, A.; Restuccia, A.; Onofri, A.; Lo Giudice, V.; Gresta, F. Species-area relationships and minimum area in citrus grove weed communities. Plant Biosyst. 2013, 149, 337-345. [CrossRef]

13. Bárberi, P.; Cozzani, A.; Macchia, M.; Bonari, E. Size and composition of the weed seedbank under different management systems for continuous maize cropping. Weed Res. 1998, 38, 319-334. [CrossRef]

14. Frenda, A.S.; Ruisi, P.; Saia, S.; Frangipane, B.; Di Miceli, G.; Amato, G.; Giambalvo, D. The critical period of weed control in faba bean and chickpea in Mediterranean areas. Weed Sci. 2013, 61, 452-459. [CrossRef]

15. USDA. Soil Taxonomy: A basic system of soil classification for making and interpreting soil surveys. In Agricultural Handbook; U.S. Department of Agriculture, Ed.; U.S. Government Printing Office: Washington, DC, USA, 1975; p. 754.

16. Brullo, S.; Scelsi, F.; Siracusa, G.; Spampinato, G. Caratteristiche bioclimatiche della Sicilia. Giornale Botanico Italiano 1996, 130, 177-185. [CrossRef]

17. Vasileiadis, V.P.; Froud-Williams, R.J.; Eleftherohorinos, I.G. Vertical distribution, size and composition of the weed seed bank under various tillage and herbicide treatments in a sequence of industrial crops. Weed Res. 2007, 47, 222-230. [CrossRef]

18. Scavo, A.; Restuccia, A.; Abbate, C.; Mauromicale, G. Seeming field allelopathic activity of Cynara cardunculus L. reduces the soil weed seed bank. Agron. Sustain. Dev. 2019, 39, 41. [CrossRef]

19. Raunkiaer, C. Life Forms of Plants and Statistical Plant Geography; Oxford University Press: Oxford, UK, 1934.

20. Mauromicale, G.; Restuccia, G.; Marchese, M. Soil solarization, a non-chemical technique for controlling Orobanche crenata and improving yield of faba bean. Agronomie 2001, 21, 757-765. [CrossRef]

21. Braun-Blanquet, J. Pflanzensoziologie; Springer: Vienna, Austria, 1964.

22. Fialho, C.M.T.; Dos Santos, J.B.; De Freitas, M.A.M.; França, A.C.; Da Silva, A.A.; Dos Santos, E.A. Fitossociologia da comunidade de plantas daninhas na cultura da soja transgênica sob dois sistemas de preparo do solo. Scientia Agraria 2011, 12, 9-17.

23. Pignatti, S. Flora d'Italia; Edagricole: Bologna, Italy, 1982.

24. Tutin, T.G.; Burges, N.A.; Chater, A.O.; Edmondson, J.R.; Heywood, V.H.; Moore, D.M.; Valentine, D.H.; Walters, S.M.; Webb, D.A. Flora Europaea, 2nd ed.; Cambridge University Press: Cambridge, UK, 1964.

25. Conti, E.; Abbate, G.; Alessandrini, A.; Blasi, C. An Annotated Checklist of the Italian Vascular Flora; Palombi: Roma, Italy, 2005.

26. Sharma, P.D. Ecology and Environment, 12th ed.; Rastogi Publications: Meerut, India, 2009.

27. Stevenson, F.C.; Légere, A.; Simard, R.R.; Angers, D.A.; Pageau, D.; Lafond, J. Weed species diversity in spring barley varies with crop rotation and tillage, but not with nutrient source. Weed Sci. 1997, 45, 798-806. [CrossRef]

28. Hyvönen, T.; Salonen, J. Biomass production of weeds in low-input and conventional cropping of cereals. Biol. Agric. Hortic. 2005, 23, 161-173. [CrossRef]

29. Sher, H.; Al-Yemeni, M.N. Ecological investigation of the weed flora in arable and non arable lands of Al-kharj area, Saudi Arabia. Afr. J. Agric. Res. 2011, 6, 901-906.

30. Milton, J.; Steven, H.; Fennimore, A. Evaluation of integrated practices for common purslane (Portulaca oleracea) management in lettuce (Lactuca sativa). Weed Technol. 2003, 17, 229-233.

31. Gratani, L.; Catoni, R.; Varone, L. Evergreen species response to Mediterranean climate stress factors. iForest 2016, 9, 946-953. [CrossRef]

32. Vengris, J.; Dunn, S.; Stacewicz-Sapuncakis, M. Life History Studies as Related to Weed Control in the Northeast. 7-Common Purslane; Technical Report No. 598; Agricultural Experimental Station, College of Food and Natural Resources, The University of Massachusetts: Amherst, MA, USA, 1972; pp. 1-45.

33. Sellers, B.A.; Smeda, R.J.; Johnson, W.G.; Kendig, J.A.; Ellersieck, M.R. Comparative growth of six Amaranthus species in Missouri. Weed Sci. 2003, 51, 329-333. [CrossRef]

34. Cristaudo, A.; Gresta, F.; Luciani, F.; Restuccia, A. Effects of after-harvest period and seed dormancy of Amaranthus species. Weed Res. 2007, 47, 327-334. [CrossRef] 
35. Cristaudo, A.; Gresta, F.; Restuccia, A.; Catara, S.; Onofri, A. Germinative response of redroot pigweed (Amaranthus retroflexus L.) to environmental conditions: Is there a seasonal pattern? Plant Biosyst. 2016, 150, 583-591. [CrossRef]

36. Holm, L.; Plucknett, D.; Pancho, J.; Herberger, J. The World's Worst Weeds: Distribution and Biology; University of Hawaii Press: Honolulu, HI, USA, 1977.

37. Chauhan, B.S.; Johnson, D.E. Seed germination ecology of Portulaca oleracea L.: An important weed of rice and upland crops. Ann. Appl. Biol. 2009, 155, 61-69. [CrossRef]

38. Burniside, O.C.; Wilson, R.G.; Weisberg, S.; Hubbard, K.G. Seed longevity of 41 weed species buried 17 years in eastern and western Nebraska. Weed Sci. 1996, 44, 74-86. [CrossRef]

39. Marshall, E.J.P.; Brown, V.; Boatman, N.; Lutman, P.; Squire, G. The Impact of Herbicides on Weed Abundance and Biodiversity; Technical Report No. PN0940; UK Pesticide Safety Directorate, Long Ashton Research Station IACR: Long Ashton, UK, 2001.

40. Forcella, F.; Wilson, R.G.; Dekker, J.; Kremer, R.J.; Cardina, J.; Anderson, R.L.; Alm, D.; Renner, K.A.; Harvey, R.G.; Clay, S.; et al. Weed seed bank emergence across the corn belt. Weed Sci. 1997, 45, 67-76. [CrossRef]

41. Benvenuti, S. Weed seed movement and dispersal strategies in the agricultural environment. Weed Biol. Manag. 2007, 7, 141-157. [CrossRef]

42. Moles, A.T.; Westoby, M. Seed size and plant strategy across the whole life cycle. Oikos 2006, 113, 91-105. [CrossRef]

43. Pakeman, R.J.; Small, J.L.; Torvell, L. Edaphic factors influence the longevity of seeds in the soil. Plant Ecol. 2012, 213, 57-65. [CrossRef]

(C) 2019 by the authors. Licensee MDPI, Basel, Switzerland. This article is an open access article distributed under the terms and conditions of the Creative Commons Attribution (CC BY) license (http://creativecommons.org/licenses/by/4.0/). 